\title{
Laser Etching: A Novel Technology to Label Florida Grapefruit
}

\author{
Preeti Sood ${ }^{1}$, Chris Ference ${ }^{2}$, Jan Narciso ${ }^{2}$, and Ed Etxeberria ${ }^{1,3}$
}

\begin{abstract}
Additional Index words. Citrus paradisi, fruit quality, post harvest decay, produce labeling

SUMMARY. Laser labeling of fruit and vegetables is an alternative means of labeling produce in which a low-energy carbon dioxide laser beam etches the surface and reveals a contrasting underlying layer. These etched surfaces can promote water loss and may increase the number of entry sites for decay-promoting organisms. The long-term effects of laser labeling on produce quality during storage have not been examined. We conducted experiments to measure water loss, peel appearance, and potential decay in laser-labeled grapefruit (Citrus paradisi) during storage. Laserlabeled fruit stored at $10{ }^{\circ} \mathrm{C}$ and two relative humidities (i.e., 95\% and $65 \%$ ) for 5 weeks showed no increase in decay compared with nonetched control fruit, suggesting that laser labeling does not facilitate decay. This was confirmed by experiments where Penicillium digitatum spores were coated on fruit surfaces before and after etching. In either case, no decay was observed. In agar plates containing a lawn of $P$. digitatum spores, the laser etching reduced germination of spores in contact areas. Water loss from etched areas and label appearance were determined during storage. Water loss from waxed etched surfaces reached control levels after $24 \mathrm{~h}$ in storage. Label appearance slowly deteriorated during 4 weeks in storage and was proportional to laser energy levels and ambient relative humidity. Waxing the labeled surface reduced water loss by $35 \%$ to $94 \%$, depending on the wax formulation used. We concluded that laser labeling provides the grapefruit industry a safe alternative to adhesive sticker labeling without enhancing decay susceptibility.
\end{abstract}

$\mathrm{L}$ aser labeling has become an alternative means of fruit labeling in many areas of the world (e.g., New Zealand, Australia, and Pacific Rim countries), approved in others (e.g., South Africa, Mexico, Canada, Argentina, Chile, and the European Union), and is currently in final approval stages by the U.S. Food and Drug Administration. The technique consists of etching the required information on the produce surface using a low-energy carbon dioxide laser beam $(10,600 \mathrm{~nm})$ (Drouillard and Rowland, 1997). Etched markings are formed in dot matrix-style letters and numbers, each dot created by a pin-hole depression. The advantages of laser labeling have been described previously (Etxeberria et al., 2006), yet some reservations linger about potential adverse effects during storage. The pinhole depressions

\footnotetext{
${ }^{1}$ University of Florida, IFAS, Citrus Research and Education Center, 700 Experiment Station Road, Lake Alfred, FL 33850.

${ }^{2}$ U.S. Department of Agriculture/Agricultural Research Service, Citrus and Subtropical Products Laboratory, 600 Avenue South, Northwest Winter Haven, FL 33881

${ }^{3}$ Corresponding author. E-mail: eje@crec.ifas.ufl.edu.
}

applied after washing and waxing disrupt the natural cuticular barrier and the protective commercial wax cover, seemingly creating open cavities that would allow for increased water loss and facilitate the entrance of decay organisms.

In previous anatomical studies using tomato (Solanum lycopersicum) and avocado (Persea americana) (Etxeberria et al., 2006), it was demonstrated that cells under the affected area of a laser pinhole developed a protective layer mostly of lignin and phenolics when stored for $4 \mathrm{~d}$ at $10{ }^{\circ} \mathrm{C}$ and $95 \%$ relative humidity $(\mathrm{RH})$. This rapid healing response, accompanied by phenolic deposition, has been observed in 'Valencia' orange (Citrus sinensis) (Brown et al.,
1979). When 'Ruby Red' grapefruit were damaged by friction with sandpaper, penetration by Penicillium digitatum was inhibited where cells at the surface produced lignin before fungal entry (Brown et al., 1979). In a related study, Yuk et al. (2007) challenged tomato fruit with Salmonella immediately after labeling and observed no migration into the tissue by the organism, suggesting that some protection is supplied by the labeling process itself.

Little information is available on the impact of this new technology on the overall quality of labeled produce, especially its effect on water loss and decay during prolonged storage. In Florida, grapefruit represents $43 \%$ of the citrus fresh market (Florida Citrus Mutual, 2008), a condition that requires extended storage, especially when transported to international destinations. The present study determined the effects of laser labeling on water loss and decay susceptibility during prolonged storage.

\section{Materials and methods}

Plant material. 'Red Ruby' grapefruit was procured from Haines City Citrus Growers Association Packinghouse in Haines City, FL. The fruit had been washed and waxed with carnuba containing $15 \mathrm{ppm}$ thiabendazole (TBZ) following established commercial practices.

Fruit LABELING. Fruit was labeled as described by Etxeberria et al. (2006) using a low-energy carbon dioxide laser etching machine (model XY Mark-10; Sunkist Growers, Fontana, CA) located at the University of Florida's Citrus Research and Education Center in Lake Alfred, FL. Individual fruit were placed against a PVC rectangular frame stabilized $10 \mathrm{~cm}$ from the laser's output. The energy level used was the recommended $0.000752 \mathrm{~W} /$ dot per $35-\mu$ s exposure with a $25 \%$ duty cycle range. Differences in applied energy are expressed

\begin{tabular}{llll}
\hline $\begin{array}{l}\text { Units } \\
\text { To convert U.S. to SI, } \\
\text { multiply by }\end{array}$ & U.S. unit & SI unit & $\begin{array}{l}\text { To convert SI to U.S., } \\
\text { multiply by }\end{array}$ \\
\hline 29,574 & $\mathrm{fl} \mathrm{oz}$ & $\mu \mathrm{L}$ & $3.3814 \times 10^{-5}$ \\
29.5735 & $\mathrm{fl} \mathrm{oz}$ & $\mathrm{mL}$ & 0.0338 \\
0.0929 & $\mathrm{ft}^{2}$ & $\mathrm{~m}^{2}$ & 10.7639 \\
1 & $\mathrm{micron}$ & $\mu \mathrm{m}^{2}$ & 1 \\
1 & $\mathrm{ppm}$ & $\mathrm{mg} \cdot \mathrm{L}^{-1}$ & 1 \\
6.8948 & $\mathrm{psi}$ & $\mathrm{kPa}$ & 0.1450 \\
$\left({ }^{\circ} \mathrm{F}-32\right) \div 1.8$ & ${ }^{\circ} \mathrm{F}$ & ${ }^{\circ} \mathrm{C}$ & $\left(1.8 \times{ }^{\circ} \mathrm{C}\right)+32$
\end{tabular}


by variations in the exposure time to the laser, and varied according to individual experiments as described below.

Selection of optimal EXPoSURE TIME. A label code containing one letter and one number ("Ml") was etched on fruit surfaces using different exposure times ranging from 30 to $140 \mu$ s. To enhance resolution, labels were rubbed gently with a cotton-tipped swab dipped in a dark, fruit-based colorant. Images of the dyed label were captured using a digital camera (Powershot S31S; Cannon, Lake Success, NY) mounted on a stereoscope (Wild Heerbrugg 165083; Leica Microsystems, Wetzlar, Germany). The surface area affected by the label was measured using image processing software developed by A. Schumann (unpublished data). The total area was calculated based on the number of pixels within the area covered by the laser depressions with 1 pixel corresponding to $50 \mu \mathrm{m}^{2}$. Five replicates per energy level were used.

Determination of WATER LOSS. Water loss from the fruit surface was measured using a modified leaf porometer (Decagon Devices, Pullman, WA). To estimate water loss as a function of energy level, an etched rectangular matrix pattern of $7 \times 8$ dots was used for each of four preselected exposure times: low $(30 \mu \mathrm{s})$, commercial standard (45 $\mu \mathrm{s})$, me$\operatorname{dium}(80 \mu \mathrm{s})$, and high $(120 \mu \mathrm{s})$. The modified leaf porometer was placed on the top of the treated area immediately after etching until a stable reading was obtained.

Water vapor diffusion from grapefruit was calculated using Eq. I based on Fick's law where "water vapor flux density" or "evaporation rate" $(\mathrm{F})$ is the product of vapor conductance (gv) and the difference between vapor concentration at the evaporating surface (Cvs) and water vapor concentration in atmosphere (Cva). Values are expressed as millimoles per square meter per second. The modified leaf porometer estimates the value for water vapor conductance (gv), which can be computed in the equation below to obtain "evaporation rate":

$$
\mathrm{F}=\mathrm{gv}(\mathrm{Cvs}-\mathrm{Cva})
$$

Vapor concentration was calculated using Eq. 2, where $\mathrm{e}_{\mathrm{a}}$ is the vapor pressure $(\mathrm{kPa})$, which is a function of temperature, and $\mathrm{p}_{\mathrm{a}}$ is the atmospheric pressure $(\mathrm{kPa})$.

$$
C v=\frac{e_{a}}{P_{2}}
$$

EFFECT OF DIFFERENT WAXES ON WATER LOSS FROM LABELED AREAS. Nine different commercial waxes were tested for their effect on moisture loss reduction from a labeled area (see Fig. 5 ). Waxes were obtained directly from the manufacturers [Deco shellac, Carnuba 505, Carnuba + TBZ, Carnuba 231, and Carnuba blend (Deco, Monrovia, CA); Citrus wax shellac and HDH Carnuba (HDH Agriproducts, Tavares, FL); and Pace Carnuba and Organic Carnuba (Pace International, Visalia, CA)]. Fruit were labeled using a single exposure time $(45 \mu \mathrm{s})$ and were then waxed using a sponge paint brush. Evaporation rate measurements of the labeled and unlabeled (control) surfaces were performed before and after waxing. Each measurement was replicated 30 times.

A separate experiment was conducted to evaluate water loss from waxed and unwaxed etched areas during storage. Etched rectangles were waxed and fruit were kept at $10{ }^{\circ} \mathrm{C}$ and $95 \%$ RH for $7 \mathrm{~d}$. Daily measurements of "evaporation rates" of the waxed label, unwaxed label, and control (no label on fruit) were carried out. For each treatment, 30 separate measurements were made.

Peel stability. The label "Florida citrus" was etched on the fruit using four exposure times $(35,45,85$, and $120 \mu \mathrm{s})$, and fruit were kept at $10{ }^{\circ} \mathrm{C}$ and $65 \%$ or $95 \% \mathrm{RH}$ for 4 weeks. Five replicates (one replicate $=$ one box $=$ 35 fruit) per exposure time and control (nonlabeled fruit) were used. Weekly examination of the label appearance and surrounding area was performed. Peel stability was determined on the basis of a visual rating scale according to the shrinkage of the skin around label as follows: $0=$ no shrinkage, $1=$ very low, 2 = low, $3=$ medium, 4 = high, 5 = very high (Fig. 1).

Decay study. Fruit treated as indicated above and stored at 95\% $\mathrm{RH}$ were examined weekly for decay symptoms for 5 weeks. Decay was categorized individually, but was reported as total decay.

Mold inOCUlation study. Fruit labeled "Florida Citrus" were subjected to four treatments: 1) inoculation of fruit before labeling, 2 ) inoculation after labeling, 3) inoculation on waxed label, and 4 ) waxing of inoculated label. Inoculum was prepared by growing $P$. digitatum Link on potato dextrose agar (BD/ Difco, Sparks, MD) plates for $7 \mathrm{~d}$. One hundred microliters of sterile $0.1 \%$ Tween 20 was placed on the plate surface and the spores were liberated from the colony and placed in sterile phosphate buffer $(0.1 \%$, $7.2 \mathrm{pH})$. Spore concentration was determined by counting cells with a hemocytometer (Hausser Scientific, Horsham, PA). Inoculum was adjusted to $10^{5}$ cells $/ \mathrm{mL}$. Inoculation was carried out by spreading a thin layer of spore suspension onto the fruit peel before and after labeling using a sterilized small brush. Inoculated fruit were stored at $10{ }^{\circ} \mathrm{C}$ and 95\% RH for 3 weeks and examined for decay weekly. Thirty replicates of one fruit each were used for all four treatments. Labeling was performed using one exposure time (45 $\mu \mathrm{s})$.

In a separate experiment, $250 \mu \mathrm{L}$ of the $P$. digitatum spore suspension was spread on agar plates, allowed to dry, labeled, and incubated at 23 ${ }^{\circ} \mathrm{C}$. In a separate experiment, spores were allowed to germinate for $72 \mathrm{~h}$ and plates were then labeled as indicated above. Etched labels were observed under a microscope immediately and $48 \mathrm{~h}$ after labeling.

\section{Results}

Optimization of exposure TIME FOR GRAPEFRUIT LABELING. A previous study demonstrated that the dot matrix style forming the alphanumerical characters of laser labels constitute superficial ruptures (pinholes) of the epidermal layer exposing the contrasting underlying tissue (Etxeberria et al., 2006). However, because the colored epidermis (flavedo) on citrus fruit is thicker than the depth of the pinholes, vegetable dye was applied to provide contrast. The visual effect of increasing laser labeling exposure time on grapefruit peel is shown in Fig. 2. At the lowest possible exposure time of $30 \mu \mathrm{s}$, the label was faint and hardly visible, whereas at the highest exposure time, the pinhole depressions merged into solid lines.

Using image processing software, the affected surface area was calculated as a factor of increasing 


\section{Research Reports}

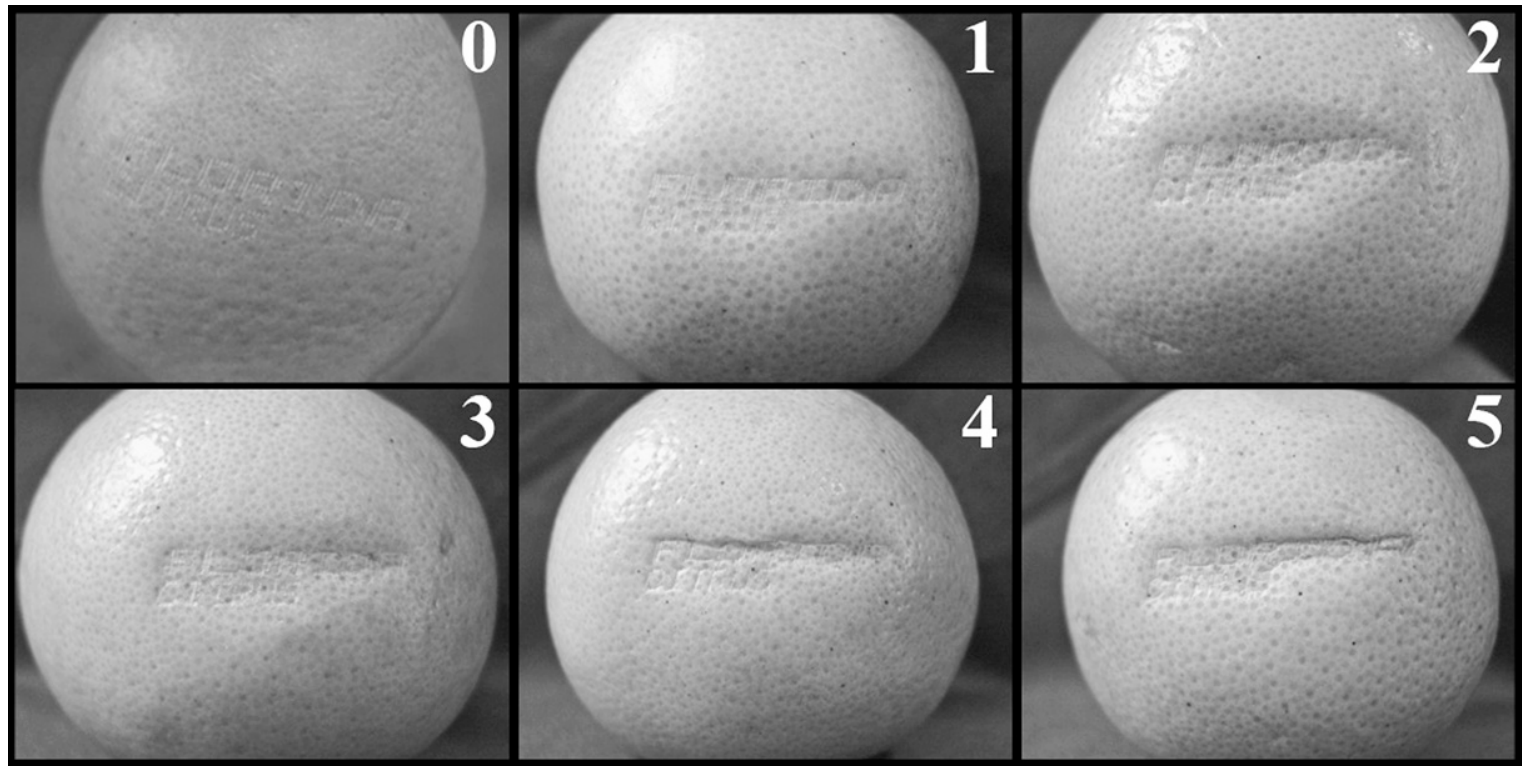

Fig. 1. Shrinkage rating scale for laser-labeled 'Ruby Red' grapefruit peel. Scale ranges from 0 (no shrinkage) to 5 (total label collapse). Fruit were labeled at $\mathbf{4 5} \mu$ s with the label "Florida Citrus" and stored at room temperature until a full range of label distortion appeared as a consequence of water loss.

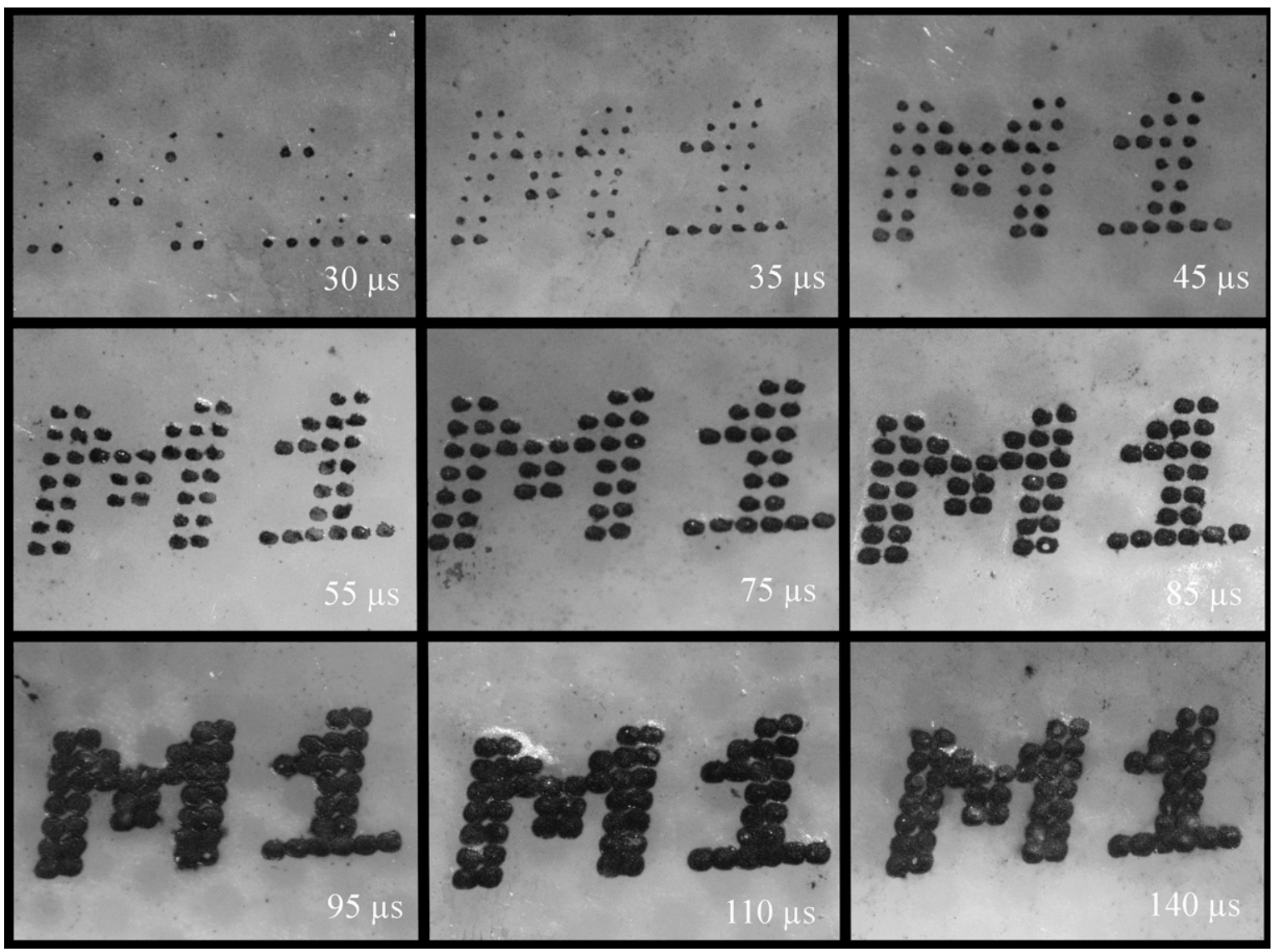

Fig. 2. A group photograph of labels etched on 'Ruby Red' grapefruit using different exposure times/energy levels. The 45- $\mu$ s photograph represents the energy level generally recommended for commercial use. Contrast of etched label was enhanced using fruit-based color. Images of the dyed label were captured using a digital camera mounted on a stereoscope. 
exposure time. In general, the area covered by the etched marking increased with higher exposure times (Fig. 3). As expected, the rate of peel surface area disruption declined at higher exposure times as pinholes began to merge.

Measurements OF WATER LOSS. Water loss from etched surfaces was measured as a function of exposure time and pinhole size (Fig. 4). For this experiment, four exposure times were selected representing low $(35 \mu \mathrm{s})$, commercially recommended $(45 \mu \mathrm{s})$, medium $(85 \mu \mathrm{s})$, and high $(120 \mu \mathrm{s})$. Water loss measurements were made immediately after labeling. As shown in Fig. 4, there was a rapid increase in the rate of water loss between 45 and $85 \mu \mathrm{s}$. Afterward, increase in the rate of water loss was negligible.

EFFECT OF WAXES ON WATER LOSS RETARDATION IN LABELED AREA. The effect of waxing on reducing water loss from etched fruit surfaces was investigated using different waxes. All nine waxes tested reduced water loss between $35 \%$ and $94 \%$ with four coatings showing over $90 \%$ reduction (Fig. 5). Citrus wax shellac resulted in the highest reduction of water loss (94\%, Fig. 5), whereas shellac resulted in moderate water loss reduction as previously described by Hagenmaier and Shaw (1991).

Water loss from unwaxed labeled areas declined with time in storage (Fig. 6). There was a steady decline in the rate of water loss up to $72 \mathrm{~h}$ after labeling, which continued more gradually thereafter. Water loss from unwaxed labeled areas never reached control levels (Fig. 6) as they did with tangerine (Citrus reticulata) $4 \mathrm{~d}$ after labeling (Sood et al., 2008). During the first $24 \mathrm{~h}$, the rate of water loss from waxed etched areas was $\approx 40 \%$ higher than control. Afterward, water loss from control and waxed labeled surfaces remained nearly identical.

Peel stability. The potential effect of water loss from the etched area on the label stability during storage was investigated at two levels of $\mathrm{RH}$. To determine the physical effect on label stability, a visual scale was created (see Materials and Methods; Fig. 1). As expected, the degree of label distortion increased with time and was inversely proportional to ambient RH (Figs. 7 and 8). After 4 weeks in storage, $\approx 40 \%$ of etched labels in fruit stored at $95 \% \mathrm{RH}$

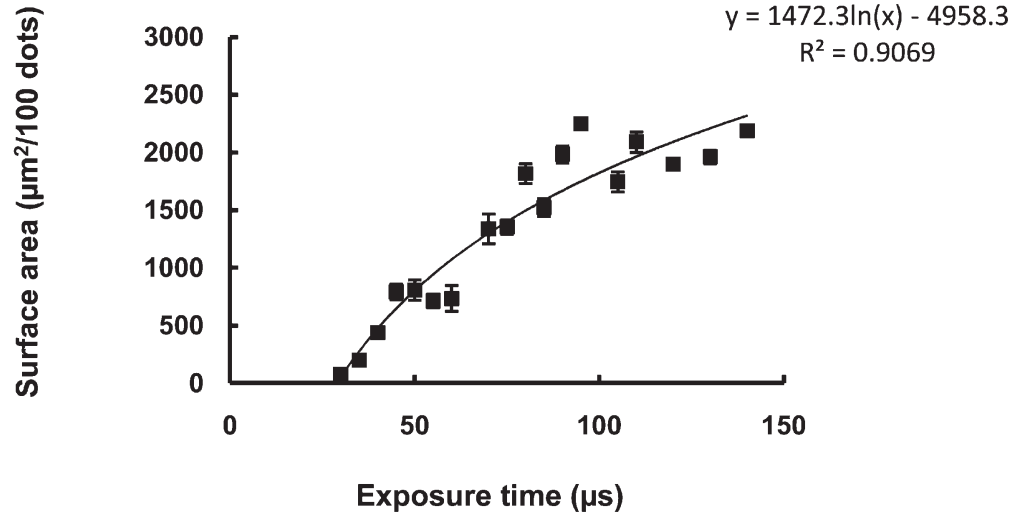

Fig. 3. Relationship between exposure time (30-140 $\mu$ s) and laser-labeled surface area (covered by 100 dots) of 'Ruby Red' grapefruit. Surface area affected by the label was measured using an image processing software developed by A. Schumann. Total area was calculated based on number of pixels within the area covered by the laser depressions with one pixel corresponding to $50 \mu \mathrm{m}^{2}\left(1 \mu \mathrm{m}^{2}=1\right.$ micron $\left.^{2}\right)$. Five replicates per energy level were used. Each point represents the average of five replicates labeled at ambient temperature. Vertical lines represent the SE.

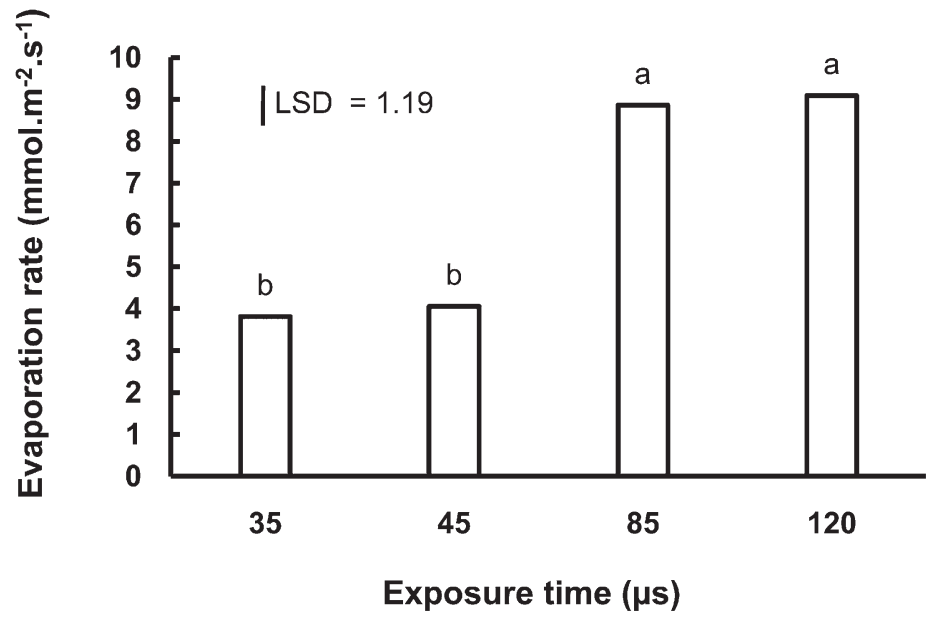

Fig. 4. Water loss from laser-etched 'Ruby Red' grapefruit peel using four different exposure times. Water loss from the etched surface was measured at ambient temperature immediately after laser labeling 30 fruit per exposure time. Vertical lines represent the SE. Data were analyzed by $t$ test. Letters atop bars indicate statistical groupings. Bars with different letters are significantly different via least significant difference (LSD) at $P=0.05$.

showed some degree of shrinkage, although most were classified as very low (Fig. 7). On the contrary, storage at $65 \% \mathrm{RH}$ resulted in substantial label shrinkage, with $\approx 98 \%$ of the fruit affected (Fig. 8). This is in sharp contrast to tangerines, which showed minimal shrinkage when stored at similar RH (Sood et al., 2008).

Decay Study. Fruit decay was followed for 5 weeks in packed grapefruit stored at $10{ }^{\circ} \mathrm{C}$ and $95 \% \mathrm{RH}$. Close attention was placed to the sites of decay, with special emphasis on the labeled area. Although different kinds of decay were noted, we report total decay for simplification. In the present study, fruit decay in fruit labeled with all four exposure times was similar to control nonlabeled fruit (Fig. 9). All decay present during the 5-week storage period was independent from the labeled areas, the most common being stem end rot. These results are analogous to those of Yuk et al. (2007) who demonstrated a lack of Salmonella migration and survival in tomato laser labels.

In citrus fruit, green mold caused by $P$. digitatum is the most common postharvest decay. Surprisingly, fruit inoculated before or after labeling 


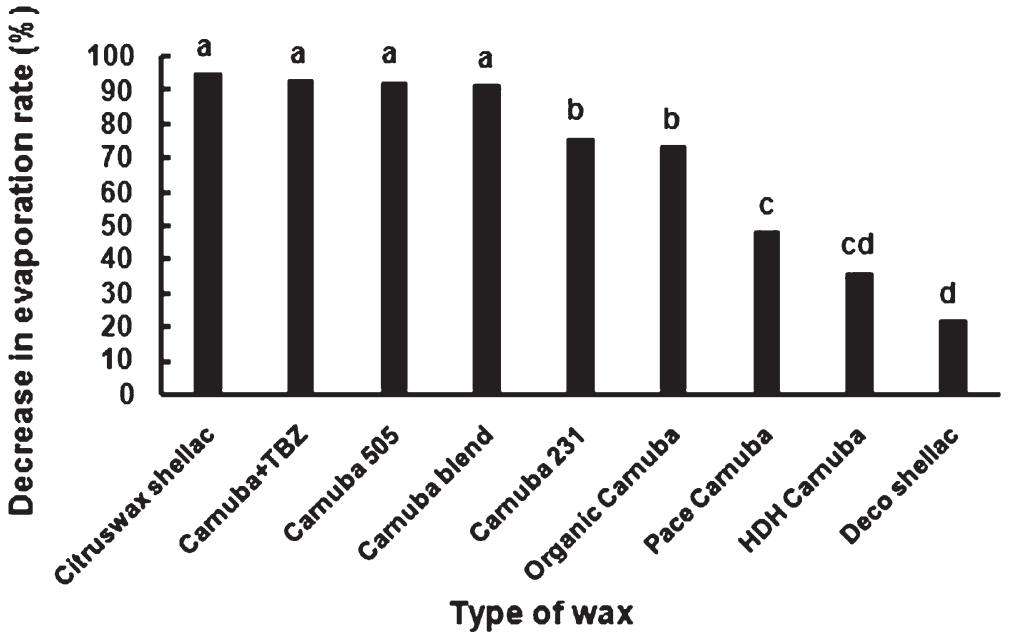

Fig. 5. Percentage decrease in the rate of water loss from laser-labeled 'Ruby Red' grapefruit peel by different commercial waxes compared with unwaxed label. Waxes were applied to 30 fruit per replication immediately after labeling and were allowed to dry for $10 \mathrm{~min}$. Waxes were obtained directly from the manufacturers [Deco shellac, Carnuba 505, Carnuba + TBZ (thiabendazole), Carnuba 231, Carnuba blend (Deco, Monrovia, CA); Citrus wax shellac, $\mathrm{HDH}$ Carnuba (HDH Agriproducts, Tavares, FL); Pace Carnuba, Organic Carnuba (Pace International, Visalia, CA)]. Water loss measurements were taken at ambient temperature using a modified leaf porometer. Bars with different letters are significantly different by $t$ tests (least significant difference $=14.7$ at $P=0.05$ ).

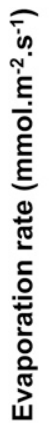

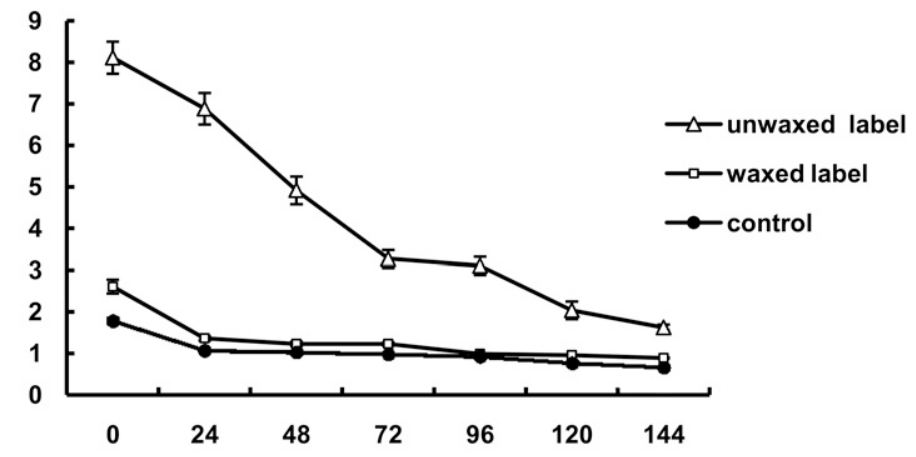

Time after labeling (h)

Fig. 6. Water loss from unwaxed label, waxed (carnuba) label, and control 'Ruby Red' grapefruit (no label) during $7 \mathrm{~d}$ of storage at $10^{\circ} \mathrm{C}\left(50.0{ }^{\circ} \mathrm{F}\right)$. Initial measurements were taken on 30 fruit immediately after labeling at ambient temperature. Vertical lines represent the SE.

with a $P$. digitatum spore suspension showed no symptoms of mold growth, even after 3 weeks in storage. On the contrary, fruit wounded and inoculated with the same spore suspension decayed within 1 week. In a separate experiment, laser labeling appeared to destroy mold spores layered on dextrose agar plates, as no germination occurred on the labeled pinholes, while the area around sustained a dense network of fungal hyphae (Fig. 10A). When spores were allowed to germinate and were then subjected to laser labeling, vegetative hyphae was eliminated from the labeled areas (Fig. 10B).

\section{Discussion}

Laser labeling of fruit and vegetables is based on etching the required information on the produce surface with permanent dot matrix alphanumerical characters or symbols. In doing so, the physical disruption of the natural epidermal and cuticular protection may introduce artifacts with potential detrimental consequences. For example, epidermal waxes, which play a vital role in retaining moisture in the fruit and vegetables (Riederer and Schreiber, 2001), are disrupted by the laser generated pinholes, potentially rendering the produce surface susceptible to water loss and secondary invasion by decay organisms.

The relationship between pinhole size and water loss was investigated as a means to establish optimal label boundaries in terms of maximal readability with minimal water loss. Our results showed that increasing labeling time beyond $45 \mu$ s substantially increased water loss (Fig. 4) proportional to pore size (Fig. 3), yet readability was optimal between 55 to $85 \mu \mathrm{s}$. Therefore, optimizing readability at the lowest range of water loss between the range 45 to $55 \mu$ s can be achieved without risking additional detrimental effects due to water loss.

During commercial operations at the packinghouse, waxing of citrus fruit precedes fruit labeling, packing, storage, and long-distance transport. Whereas sticker labels do not suffer physical deterioration in storage, the loss of water from the etched labels (Fig. 6) may alter the physical appearance of the fruit's surface, thereby distorting the label (Figs. 1, 7, and 8 ) and making it less effective and appealing. As reported, $\mathrm{RH}$ has a direct effect on the rate of moisture loss from produce surfaces (Forbes and Watson, 1992). Our data indicated that a considerable portion of the fruit showed some level of shrinkage, making the label unreadable, especially fruit stored at $65 \% \mathrm{RH}$ for 4 weeks. Even the lowest shrinkage (or shriveling) obtained at $95 \% \mathrm{RH}$ can be sufficient to make the fruit less appealing. It is likely that at some point in the commercial chain of events, fruit may encounter lower than 65\% RH. Although the natural healing process of the label pinholes reduced water loss to control levels after $4 \mathrm{~d}$ (Fig. 6; Etxeberria et al., 2006), the addition of a secondary wax coat after labeling reduced water loss to control levels immediately after application (Fig. 6), which delayed or prevented unnecessary shrinkage. Inasmuch as a second wax application is not commercially feasible at the moment, methods should be developed to address this 


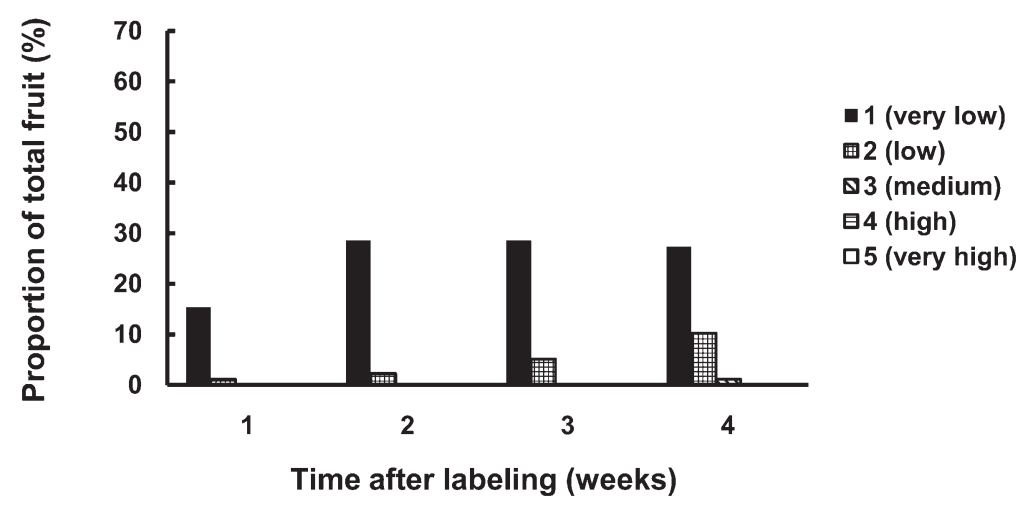

Fig. 7. Peel shrinkage of etched 'Ruby Red' grapefruit during storage at $10{ }^{\circ} \mathrm{C}(50.0$ ${ }^{\circ} \mathrm{F}$ ) and $95 \%$ relative humidity. Shrinkage severity was determined on 175 unwaxed fruit per exposure time using a visual scale of 0 (very low or no shrinkage) to 5 (very high or total label collapse) depicted in Fig. 1.

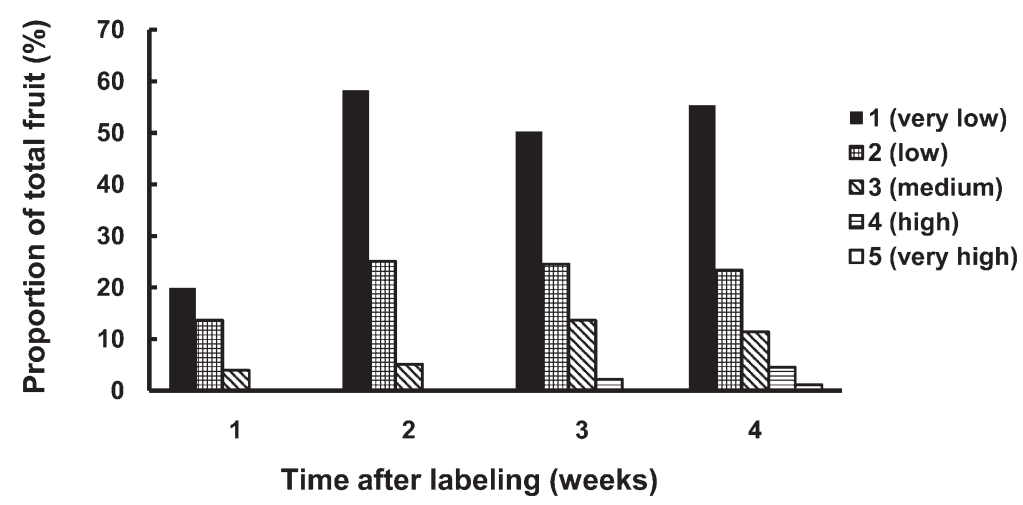

Fig. 8. Peel shrinkage of etched 'Ruby Red' grapefruit during storage at $10{ }^{\circ} \mathrm{C}(50.0$ ${ }^{\circ}$ F) and $65 \%$ relative humidity. Shrinkage severity was determined on 175 unwaxed fruit per exposure time using a visual scale of 0 (very low or no shrinkage) to 5 (very high or total label collapse) depicted in Fig. 1 .

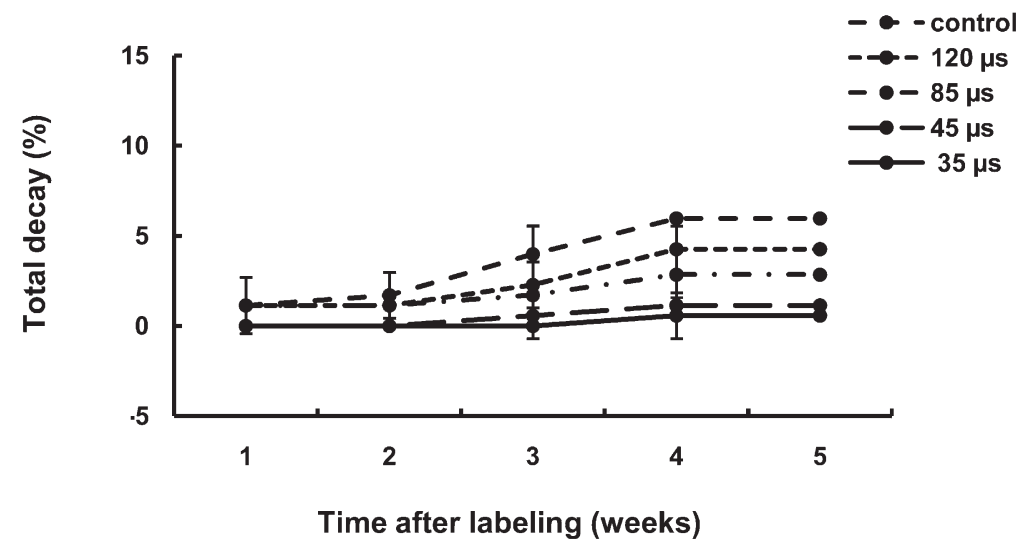

Fig. 9. Total decay of labeled 'Ruby Red' grapefruit in storage. Fruit were labeled using 4 exposure times $(35,45,85$, and $120 \mu \mathrm{s})$ at ambient temperature and stored at $10{ }^{\circ} \mathrm{C}\left(50.0^{\circ} \mathrm{F}\right)$ and $95 \%$ relative humidity. There was no decay associated with the laser label. Each point represents the average of five boxes, each box containing 50 fruit. Vertical lines represent the SE.

problem in the future to avoid loss of visual appeal and functionality.

Citrus fruit are relatively nonperishable, and can normally be stored for long periods (Kader, 2002). Grapefruit can be stored at 10 to $15{ }^{\circ} \mathrm{C}$ and $90 \%$ to $95 \% \mathrm{RH}$ for 5 to 8 weeks (Grierson, 1974). In general, citrus fruit are vulnerable to various decay organisms during storage, especially Penicillium spp. (Kinay et al., 2001). Penicillium spp. growth necessitates the rupture of the produce surfaces (Eckert and Brown, 1986), a condition seemingly created by the laser pinholes. Our data from fruit held at $10{ }^{\circ} \mathrm{C}$ and $95 \% \mathrm{RH}$ for 5 weeks showed no decay symptoms associated with the etched area. Brown et al. (1979) found that accumulation of lignin occurred rapidly in injuries at $30{ }^{\circ} \mathrm{C}$ and $\mathrm{RH}$ over $90 \%$, likely creating rapid protection. $\mathrm{Al}$ though our experiments were conducted at $10{ }^{\circ} \mathrm{C}$, either formation of lignin or loss of humidity from the pinhole area appeared sufficient to deter decay. This is probable because $P$. digitatum is a wound parasite and does not actively invade intact plant tissue. We often found decayed fruit in the etched fruit samples; however, it was no different from that of nonetched fruit control samples. The lack of decay associated with etched areas was further substantiated by experiments exposing the fruit to two worst possible conditions. Whether coated with a high concentration of $P$. digitatum spores before etching, or a layer of spores coated over the freshly etched surface, no fruit decay took place from the labeled area during 4 weeks in storage. The lack of decay by mold was unexpected given that, in one instance, fruit were essentially inoculated with $P$. digitatum spores immediately after etching. These data, and especially those of Fig. 10 showing lack of spore germination on etched areas and the elimination of vegetative hyphal growth by etching, demonstrate that the laser labeled areas do not have increased susceptibility to decay organisms in grapefruit.

We observed appreciable differences in the postharvest behavior of laser-labeled fruit between grapefruit and tangerines, especially on the efficacy of different waxes in preventing water loss and in label shrinkage (Sood et al., 2008). Differences in wax efficiency are difficult to reconcile considering that surface area affected by different labeling times was nearly identical in both types of citrus and coverage by waxes is expected to be alike. However, previous work by the authors showed that any treatment of fruit peel affects the cuticle, and therefore, could have an effect on 


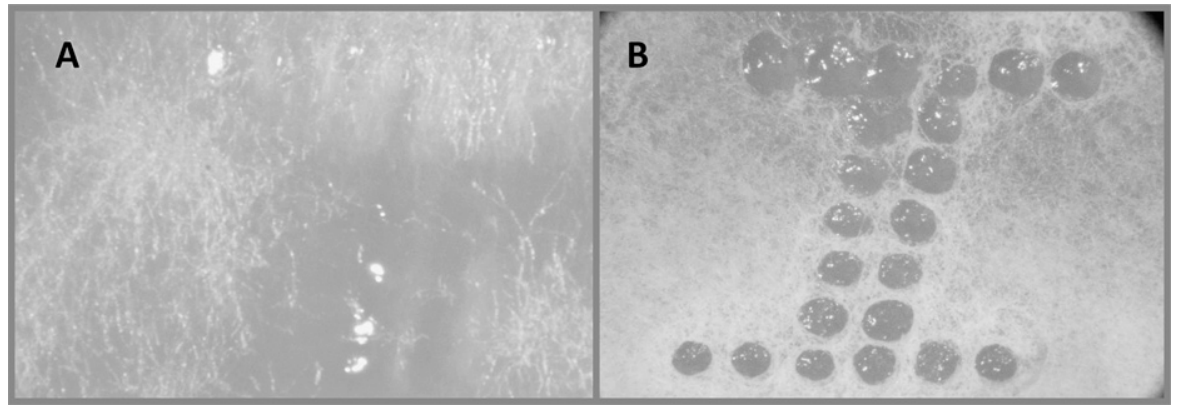

Fig. 10. (A) Penicillium digitatum hyphae grown for $72 \mathrm{~h}$ on potato dextrose agar after a lawn of spores was laser labeled at $45 \mu \mathrm{s}$. (B) Laser labeling of $72 \mathrm{~h}$ grown $P$. digitatum hyphae at $\mathbf{4 5} \mu \mathrm{s}$.

the way that additional coatings are laid down. Rearrangement of the epicuticular waxes, even in different areas on the same fruit, will determine the coverage of waxes applied to the peel (data not shown). Also, the differences in peel topography between the tangerine and the grapefruit may be an added factor in the uniformity of the applied coating. The larger number of grapefruit affected by label shrinkage, however, is likely due to the higher percentage of water loss through the labeled areas compared with nonlabeled areas.

Although restricted to one commodity, this study shows that laser labeling of grapefruit is a viable option to identify produce with a permanent tag. When compared with sticker-labeled fruit, a laser-labeled commodity is relatively tamper free and the fruit quality remains high as the invasion of the epidermis does not incite decay, provide an avenue for food pathogens, and water loss is easily controlled.

\section{Literature cited}

Brown, G.E., M.A. Ismail, and C.R. Barmore. 1979. Lignification of injuries to citrus fruit and susceptibility to green mold. Proc. Florida State Hort. Soc. 91: 124-126.

Drouillard, G. and R.W. Rowland. 1997. Method of laser marking of produce. Patent no. 5660747. U.S. Department of Commerce, Patent and Trademark Office, Washington, DC.

Eckert, J.W. and G.E. Brown. 1986. Postharvest citrus diseases and their control, p. 315-360. In: W.F. Wardowski, S. Nagy, and W. Grierson (eds.). Fresh citrus fruits. AVI Publishing, Westport, CT.

Etxeberria, E., W.M. Miller, and D. Achor. 2006. Anatomical and morphological characteristics of laser labeling. HortTechnology 16:527-532.

Florida Citrus Mutual. 2008. Annual statistical report for 2006-2007 Florida citrus harvesting season. 17 Feb. 2009. <http://www.flcitrusmutual.com/files/ 8d69285e-786f-4769-8.pdf>.
Forbes, J.C. and R.D. Watson. 1992. Effects of packaging on post-harvest deterioration, p. 291-294. In: J.C. Forbes and R.D. Watson (eds.). Plants in agriculture. Cambridge University Press, Cambridge, UK.

Grierson, W. 1974. Chilling injury in tropical and subtropical fruit. V. Effect of harvest date, degreening, delay storage and peel color on chilling injury of grapefruit. Proc. Trop. Reg. Amer. Soc. Hort. Sci. 18:66-73.

Hagenmaier, R.D. and P.E. Shaw. 1991. Permeability of shellac coatings to gases and water vapor. J. Agr. Food Chem. 39: 825-829.

Kader, A.A. 2002. Postharvest biology and technology: and overview, p. 39-48. In: A.A. Kader (ed.). Postharvest technology of horticultural crops. Regents of the University of California, Division of Agricultural and Natural Resources, Oakland.

Kinay, P., M. Yildiz, F. Yildiz, N. Delen, and N. Tosun. 2001. Control of postharvest pencillium decay of citrus fruits with antagonistic yeast and chemical fungicides, p. 383-385. Proc. 4th Intl. Conf. Postharvest.

Riederer, M. and L. Schreiber. 2001. Protecting against water loss: Analysis of the barrier properties of plant cuticles. J. Expt. Bot. 52:2023-2032.

Sood, P., C. Ference, J. Narciso, and E. Etxeberria. 2008. Effect of laser labeling on the quality of tangerines during storage. Proc. Florida State Hort. Soc. 121:297-300.

Yuk, H.G., W.R. Benjamin, and K.R. Schneider. 2007. Infiltration and survival of Salmonella species on tomato surfaces labeled using low energy carbon-dioxide laser device. HortTechnology 17:67-71. 